\title{
VARIATIONS IN THE TRIBUTARIES OF INFERIOR VENA CAVA - AN ANATOMICAL STUDY IN 50 CADAVERS
}

\author{
Biswabasi Mohapatra ${ }^{1}$, Parimala Sirikonda ${ }^{* 2}$, Sirisha Bandi ${ }^{3}$, Abid Ali 4. \\ ${ }^{1}$ Professor of Anatomy, Bhaskar Medical College, Hyderabad, Telengana State, India. \\ ${ }^{* 2}$ Associate Professor, Department of Anatomy, Bhaskar Medical College, Hyderabad, Telengana \\ State, India. \\ ${ }^{3,4}$ Assistent Professor, Department of Anatomy, Bhaskar Medical College, Hyderabad, Telengana \\ State, India.
}

\section{ABSTRACT}

Objectives: To document the variations in the tributaries of inferior vena cava (IVC) with double common iliac veins, retro aortic renal veins and to establish embryological and clinic-anatomical correlations of such variation. Materials and Methods: The findings were noted after thorough and meticulous dissection of the abdomen of 50 cadavers in the department of Anatomy, Bhaskar Medical College, India. Photographic documentation of the variation was also made.

Results: Variations were reported in 2 cadavers.

1) In one cadaver the left renal vein, after its origin from the kidney passed obliquely behind the abdominal aorta, joined the IVC at the level of $3^{\text {rd }}$ lumber vertebra below the attachment of right crus of diaphragm. Left renal artery was normal in position.

2) In another cadaver, there was a communication between the right internal and external iliac veins at the pelvic brim anterior to the sacroiliac joint. From there two right common iliac veins, one appeared as continuation of internal iliac vein(common iliac vein I) and the other as a continuation of external iliac vein (common iliac vein II) ran upwards to join the IVC.

Conclusion: The variation can be explained in the light of embryological development. In addition, knowledge of such variation is important for carrying out surgical procedures in the abdomen.

KEY WORDS: Inferior vena cava, common iliac vein, retro aortic renal vein, abdominal aorta.

Address for Correspondence: Dr. Parimala Sirikonda, Associate Professor, Department of Anatomy, Bhaskar Medical College, Hyderabad, Telengana State, India. E-Mail: pari.siri@gmail.com

Access this Article online

Quick Response code

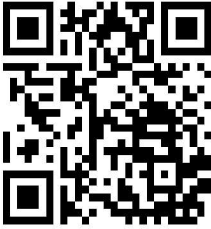

DOI: $10.16965 /$ ijar.2018.105

Journal Information

International Journal of Anatomy and Research

ICV for 2016 ISSN (E) 2321-4287 | ISSN (P) 2321-8967

90.30

https://www.ijmhr.org/ijar.htm

DOI-Prefix: https://dx.doi.org/10.16965/ijar

Article Information

Received: 03 Jan 2018

Peer Review: 03 Jan 2018

Revised: None
Accepted: 03 Feb 2018

Published (O): 05 Mar 2018

Published (P): 05 Mar 2018

\section{INTRODUCTION}

The inferior vena cava conveys blood to the right atrium from all structures below the diaphragm. The majority of its course is within the abdomen, but a small section lies within the fibrous pericardium in the thorax. It is formed by the junction of the common iliac veins anterior to the fifth lumbar vertebral body, a little to its right.
It ascends anterior to the vertebral column, to the right of the aorta. (It is contained in a tunnel completed by a band of liver tissue). Numerous anomalies may occur in the anatomy of the ivc, mostly related to its complex formation. It is sometimes replaced, below the level of renal veins, by two more or less symmetric vessels, often associated with the failure of interconnection 
between the common iliac veins, and as a result of persistence on the left side of a longitudinal channel (casually the supra cardinal or sub cardinal vein) that normally disappears in early fetal life [1].

The position of the iliac veins is described according to the corresponding arteries and the variations of the iliac veins and their relationships can be important in retroperitoneal surgical interventions such as the superior hypogastric neurectomy and hysterectomy as well as in the interpretation of the pelvic imaging, particularly computed tomography (CT) scanning or in the magnetic resonance $[2,3]$.

The objective of our study is to discuss the embryological reasons for these kind of variations in IVC and their clinical significance.

\section{MATERIALS AND METHODS}

This study was carried out in 50 formalin fixed cadavers during the routine gross anatomy dissections for the undergraduate students over a period of 6 years. (2011-2017), in the department of Anatomy, Bhaskar Medical College, Hyderabad, India. The inferior vena cava was traced proximally towards the liver and distally towards the common iliac veins draining into IVC.

\section{OBSERVATIONS}

Among the 50 cadavers, variations were found in 2 cadavers.

Cadaver 1: In this cadaver, the left renal vein, after its origin from the kidney passed obliquely behind the abdominal aorta, joined the IVC at $3^{\text {rd }}$ lumbar vertebra below the attachment of right crus of diaphragm . Its length was $7.6 \mathrm{cms}$, diameter-1.8 cms. Its posterior relations were origin of left psoas major muscle, 3 rd lumbar vertebra. Left renal artery was normal in position. The left suprarenal vein passed in front of it and joined the left renal vein. [fig. 1]

Cadaver 2: In this cadaver, tributaries and relation of right external and internal iliac veins to the corresponding arteries were all normal. There was a communication between the right internal and external iliac veins at the pelvic brim anterior to the sacroiliac joint (fig.3). From there two right common iliac veins, one appeared as a continuation of internal iliac vein (common iliac vein I) and the other as a continuation of external iliac vein (common iliac vein II) ran upwards to join inferior vena cava. Right common iliac vein I, joined left common iliac vein at right side of 5 th lumbar vertebra to form IVC and right common iliac vein II joined $2.5 \mathrm{~cm}$ above this to the IVC (fig.3) independently. The right common iliac artery was anterior to and in between these two tributaries of inferior vena cava (fig.2\&3).

Fig. 1: Shows the retroaortic left renal vein and its relations.

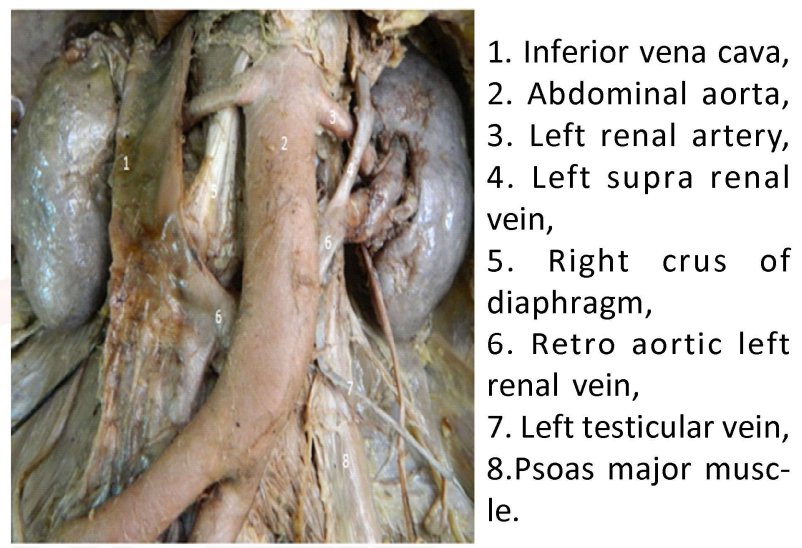

Fig. 2: Shows formation of inferior vena cava. Right common Iliac vein I joins with left common iliac vein to form the Inferior vena cava.

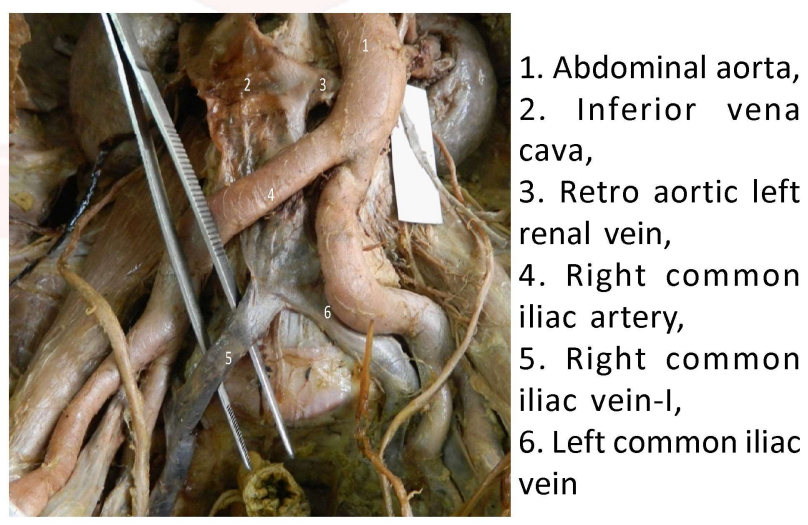

Fig. 3: Showing two common iliac veins on right side and a Communication between the right external and internal iliac Veins after removal of the abdominal aorta.

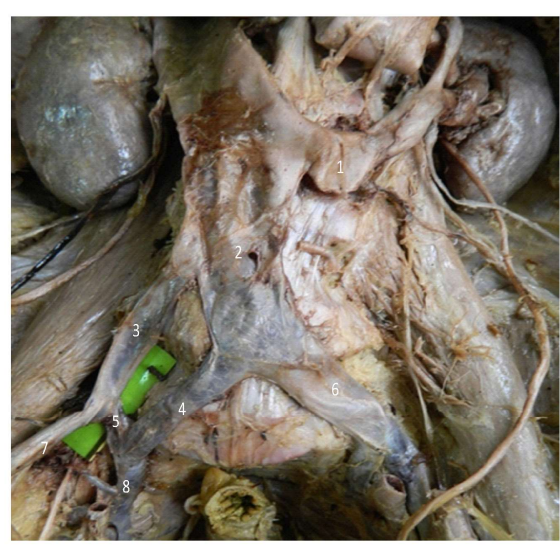
1. Left retro aortic vein,

2. Inferior vena cava,

3. Right common iliac vein-I, 4. Right common iliac vein-II, 5. Communication between two right common iliac veins, 6. Left common iliac vein, 7. Right external iliac vein, 8. Right internal iliac vein 


\section{DISCUSSION}

Cadaver 1: Occurrence of retroaortic left renal vein has been explained by authors embryologically. Their incidence is found to be very low.

Embryogenesis: Three pairs of cardinal veins contribute to the inferior vena cava and its tributaries [7]. Embryogenesis of IVC is a complicated process involving development, regression, anastomosis and replacement of three pairs of venous channels; posterior cardinal, subcardinal and supracardinal veins [4].

IVC and its tributaries start to develop by 6 th week of foetal life. Development is completed by 8 th week. Posterior cardinal veins being dominant at 6 weeks, subcardinal at 7 weeks and supracardinal at about 8 weeks [7].

The subcardinal veins intercommunicate by a preaortic anastomotic plexus, which later constitute part of the left renal vein crossing anterior to the abdominal aorta[10].

The supracardinal veins communicate freely with each other through a medium of azygos lines and subcentral veins (dorsal to abdominal aorta). Most cranial of these connections, together with the supracardinal-subcardinal and inter subcardinal anastomoses complete a venous ring around the aorta below the origin of the superior mesenteric artery, termed the 'renal collar' (Huntington 1920). Right supracardinal vein persists. It forms greater part of post renal segment of inferior vena cava. Proximally supracardinal veins anastomose with right subcardinal vein and forms part of renal collar. The renal collar configuration about the aorta is clear at the level of renal vein. Left supracardinal vein disappears. Some of the renal collar formed by anastomosis between it and left subcardinal vein persists as left renal vein. The left renal vein derives from the intersubc-ardinal anastomosis which courses anteriorly to the aorta. Retroaortic left renal vein occurs by regression of the intersubcardinal anastomosis and renal drainage through retroaortic intersu-pracardinal anastomosis $[8,11]$. But multiple midline anastomosis can occur to variable distances inferiorly. It may lead to retention of longer segment of the left supracardinal vessel. This was shown by Kottra and Cactelino [9]. The dorsal crossing may occur several centimeters below left renal vein [5]. Persistence of this can explain, formation of retroaortic left renal vein and its joining with inferior vena cava at such a lower level as in our case.

The frequencies of retro-aortic left renal vein anomalies according to various authors are as follows:

Reed et al-by CT-8/433 (1.8\%),Hoeltl, by CT-29/ 4520, at operation-6/215 (0.6\%), at dissection4/354 (1.1\%), Martinez-Almagro-by CT-4/170, by dissection-2/116 (1.7\%), Trigaux et al by CT-38/ 1014 (3.7\%), Arslan et al, by CT-19/1125 -( 1.7\%), Karazincir et al, by US-3/137 (2.2\%). [6]

According to previous study the incidence of retroaortic renal vein was reported to be 0.6 to $3.7 \%$, In our study we found 1 case of retroaortic left renal vein in 50 cadaveric dissection. Thus our work tallies with previous work.

Retroaortic vein may be clinically silent may remain unnoticed unless discovered accidentally during operation or diagnosis [6].

Rarely the compression of retroaortic renal vein may result in periureteric varices, venous hypertension and haematuria. During renal surgery undiagnosed venous anomalies may lead to major complications. There may be significant haemorrhage or damage to vascular structures. In some centres retroaortic renal veins are relative contraindications to donor nephrectomy [12]. It is a clinically important observation which should be noted by vascular surgeons, oncologists and traumatologists [6]

Cadaver 2: The parts of right external and internal iliac veins proximal to their communication can be called as common iliac veins. The communication can play an important role. By becoming a part of external iliac vein, join with internal iliac vein to form common iliac vein I. It can also become a part of internal iliac vein and join with the external iliac vein to form the common iliac vein II. As there are two right common iliac veins, blockage of one by a thrombus for some reason can allow blood flow through the other. The part of Inferior vena cava between the joining of two common iliac veins may have developed from right posterior cardinal vein. In surgery of nearby areas the surgeon should be aware of this variation or else these may be injured and can cause profuse 
bleeding. The cause of occurrence of two such variations like this cannot be explained. It can be told that aberrant development of venous system (cardinal veins) for some unknown reasons can cause such anomalies of IVC system [4 ]

\section{CONCLUSION}

The anatomical variations of the IVC constitute congenital morphologic differences observed in human body although most of them do not cause functional damage, they can be relevant during surgical procedures. This anatomical curiosity should be kept in mind by clinicians, pelvic surgeons and anatomists who are to manipulate this anatomical area.

\section{ACKNOWLEDGEMENTS}

We are grateful to Dr. K.V. Vijaya Saradhi- Professor of Anatomy and faculty members of Anatomy Department of our college for supporting us in this work.

\section{Conflicts of Interests: None}

\section{REFERENCES}

[1]. Susan standring Harold Ellis, Jeremiah c Healy et al. Gray's Anatomy, The Anatomical basis of clinical practice. $39^{\text {th }}$ ed.. London Churchill Livingstone 2011. P.1120.

[2]. Edwards WR. Hysterectomy, massive transfusion and packing to control haemorrhage from pelvic veins in the course of bilateral oophorectomy. Aust N Z J obstetric Gynaecol. 1996;36:82-84.

[3]. Keating EM, Ritter MA, Faris PM. Structures at risk from medically placed acetabular screcus. J Bone joint surg Am. 1990;72:509-511.
[4]. Artico D, Lorenzini P, Mancini P, Gobbi S, Cartois V. David. Radiological evidence of anatomical variation of the inferior vena cava; Report of two cases. Surgical and Radiological Anatomy 2004;26:153156.

[5]. Clovis Luis Konopka, Mercelo Salame, Georgia Andrade Padulla, Raquel Rodrigues Muradas, Julio Cesar Batistella; Agenesis of inferior vena cava associated with deep venous thrombosis, J Vasc Bras 2010;9:196-199.

[6]. Dong-soo kyung, Jae-Ho Lee, Deuk -yong shin et al. Double retro aortic renal vein, anatomy and cell biology.2012;1-3.

[7]. Mayo J ,Gray R, St Louis E et al. Anomalies of the inferior vena cava. AJR Am J Roentgenol 1983;140:339-345.

[8]. Kellman GM, ALpern MB, Sndler MA, et al. computed tomography of vena caval anomalies with embryologic correlation. Radiographics. 1988;8:533-56.

[9]. Kottra JJ, Castellino RA. The circumaortic left renal vein . Radiology; 1970;95:141-143.

[10]. Peter L, Willams Lawrence H, Bannister Martin M, Berry patrica Collins Mary Dyson Jullian E, Dussek Mark. W. J. Ferguson, "Gray's Anatomy",Embryonic circulation, $38^{\text {th }}$ edition,Churchill Livingstone, London, 1999; p 324-325

[11]. Royal SA, Callen PW. CT evalution of anomalies of the inferior vena cava and left renal vein. AJR Am J Roentgenol.1979;132:759-63.

[12]. Walker TG, Geller SC, Delmonico FL et al; Donor renal angiography:its influence on the decision to use the right or left kidney. AJR Am J Roentgenol 1988;151:1149-1151.

How to cite this article:

Biswabasi Mohapatra, Parimala Sirikonda, Sirisha Bandi, Abid Ali.

VARIATIONS IN THE TRIBUTARIES OF INFERIOR VENA CAVA - AN

ANATOMICAL STUDY IN 50 CADAVERS. Int J Anat Res 2018;6(1.3):5034-5037. DOI: 10.16965/ijar.2018.105 